\title{
VARIATION OF THE INTERCELLULAR SPACE IN THE ESOPHAGEAL EPITHELIUM IN RESPONSE TO HYDROCHLORIDRIC ACID INFUSION IN PATIENTS WITH EROSIVE ESOPHAGITIS
}

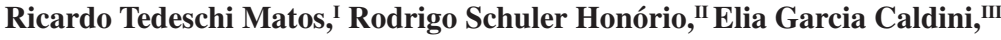 \\ Claudio Lyoiti Hashimoto, ${ }^{\mathrm{I}}$ Marcelo Alves Ferreira, ${ }^{\mathrm{III}}$ Tomás Navarro- \\ Rodriguez $^{\mathrm{I}}$
}

doi: 10.1590/S1807-59322009000700011

Matos RT, Honório RS, Caldini EG, Hashimoto CL, Ferreira MA, Navarro-Rodriguez T. Variation of the intercellular space in the esophageal epithelium in response to hydrochloridric acid infusion in patients with erosive esophagitis. Clinics. 2009;64(7):669-74.

ABSTRACT: The purpose of this study was to compare esophageal infusion with $0.1 \mathrm{~N}$ hydrochloridric acid $(\mathrm{HCl})$ to esophageal infusion with saline in patients presenting with typical gastroesophageal reflux symptoms and erosive esophagitis.

METHODS: Upper gastrointestinal endoscopy was performed on 44 prospective subjects, 29 of whom were included in the study. Eighteen patients presented with normal esophagi (Control Group "C"), nine of whom were infused with $\mathrm{HCl}$ and nine with saline. Eleven patients presented with erosive esophagitis (Lesion Group "L"), five of whom were infused with $\mathrm{HCl}$ and six with saline. Biopsies of the esophageal mucosa were collected before and after infusions.

RESULTS: No statistically significant difference was found between the two types of infusions in terms of the dilation of the intercellular space of the esophageal epithelium, regardless of the status of the patient.

CONCLUSIONS: Response to $\mathrm{HCl}$ infusion cannot be used as a marker for gastroesophageal reflux disease.

KEYWORDS: Gastroesophageal Reflux; Dilated; Intercellular Space; Epithelium; Esophagus

\section{INTRODUCTION}

Gastroesophageal reflux disease (GERD) is a chronic disorder resulting from reflux of a portion of the duodenogastric content into the esophagus or adjacent organs, resulting in a variable spectrum of esophageal or extraesophageal symptoms or signs, including tissue lesions. ${ }^{1}$

In Brazil, $12 \%$ and $7.3 \%$ of the population were reported to have pyrosis and GERD, respectively. This translates to

\footnotetext{
${ }^{\mathrm{I}}$ Department of Gastroenterology, Faculdade de Medicina da Universidade de São Paulo - São Paulo/SP, Brazil.

II Laboratory of Medical Investigation in Hepatic Pathology, Faculdade de Medicina da Universidade de São Paulo - São Paulo/SP, Brazil.

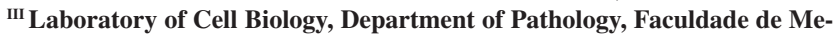
dicina da Universidade de São Paulo - São Paulo/SP, Brazil.

Email: ritedeschi@yahoo.com.br

Tel: 55193301.1910

Received for publication on April 07, 2009

Accepted for publication on April 25, 2009
}

approximately 12 and a half million people total. ${ }^{2}$

It should be stressed that the lack of esophageal mucosa lesions observed during upper gastrointestinal endoscopy (UGIE) does not rule out a diagnosis of GERD, since $50 \%$ of the patients with typical symptoms present with normal UGIE results. ${ }^{3}$

Despite the existence of several complementary tests, such as contrast-enhanced radiological examination of the esophagus and 24-h pH-metry tests, the search for new markers of GERD continues. The histopathology of the esophagus mucosa has shown that basal cell hyperplasia of the squamous epithelium and the papillae extend more than two-thirds of the distance to the epithelial (elongation of the papillae). These phenomena are considered to be useful parameters in the diagnosis of esophagitis. ${ }^{4,5}$ Other histological markers of GERD include dilated intercellular space (DIS), the presence of balloon cells with pyknotic nuclei, dilated intrapapillary vessels, acanthosis and 
infiltration by intra-epithelial eosinophils and by Langerhans cells. ${ }^{6}$

Biopsies have a limited value in the diagnosis of GERD and must be obtained from tissue approximately 2.5 to 3.0 $\mathrm{cm}$ above the Z-line, since normal individuals present with minimal histological alterations in the junctional zone. ${ }^{6,7}$

Electron microscopy has enabled the detection and assessment of DIS in the esophageal epithelium and revealed that, in erosive as well as non-erosive GERD, DIS is one of the earliest morphological changes in the esophageal epithelium. ${ }^{8,9}$ This alteration could indicate that the full recovery of the esophageal mucosa has not yet occurred in some patients presenting with a recurrence of GERD. It is questionable, however, whether DIS of the esophageal mucosa can explain the persistence of symptoms in patients after they have been classified as cured based on UGIE findings. It has been shown that symptoms in the esophageal body are perceived by patients as being regionalized. Patients with non-erosive reflux disease (NERD) are more sensitive to acid in the proximal esophageal region than those with GERD, in whom erosive esophagitis has a normal 24-h pHmetry. ${ }^{10}$ Dilated intercellular space occurs along the distal and proximal esophagus in NERD patients and could explain the enhanced perception of proximal acid reflux. ${ }^{11}$

The significance of DIS in the esophageal epithelium in GERD patients is still under debate. It has been identified in vitro by means of acid infusion in the rabbit esophagus ${ }^{12}$ and in GERD patients. ${ }^{89}$ The high incidence of GERD recurrence could be due to DIS. It can be further inferred that these are the potential mechanisms of the symptoms observed in this patient population.

It is known that DIS is better identified when located near the upper edge of the erosion than when located in the normal adjacent mucosa in patients with erosive esophagitis. ${ }^{13}$ It can also be present in $8 \%$ of control group patients. ${ }^{14}$ Vieth et al. pointed out the need for pathologists to define better GERD diagnostic criteria; they proposed the hypothesis that the distal esophagus is a locus minoris resistentiae. ${ }^{13}$

A follow-up ${ }^{15,16}$ study of patients with erosive GERD and NERD before and after proton pump inhibitor treatment was performed. They found a complete regression of the DIS of the patients after three and six months of treatment, and no statistical difference was found between the patient groups. In addition, an improvement in patient clinical symptoms was observed, indicating that this is a good parameter for evaluating scarring and clinical management of patients with NERD.

\section{AIMS}

The objective of this study was to determine whether the infusion of $0.1 \mathrm{~N}$ hydrochloridric acid $(\mathrm{HCl})$ or $0.9 \%$ saline solution $(\mathrm{NaCl})$ into the esophageal mucosa induces dilation of the intercellular space of the esophageal epithelium. We compared the responses in patients with erosive esophagitis showing typical GERD symptoms to those without GERD symptoms.

\section{PATIENTS AND METHOD}

\section{Patients}

Patients were required to give written informed consent. This study was approved by the review board for human and experimental studies of the University of São Paulo School of Medicine (CAPPesq-HCFMUSP).

This study involved 44 patients between the ages of 18 and 70 years who had been referred for UGIE due to epigastric pain, pyrosis, regurgitation or other dyspeptic symptoms. From this total, 15 patients were excluded for presenting clinical profiles consistent with GERD without erosive disease. Patients who presented with esophageal varices, esophageal gastric neoplasia, duodenal neoplasia, esophageal stenosis, pyloric stenosis or Barrett's esophagus were also excluded from this study.

The patients were randomized into two experimental procedures, those receiving an infusion of $0.1 \mathrm{~N} \mathrm{HCl}$ and those receiving an infusion of $0.9 \% \mathrm{NaCl}$ (for control purposes).

\section{Method}

\section{Endoscopy and infusion of $\mathrm{HCl}$ or $\mathrm{NaCl}$}

The UGIE was performed according to the standards of the facility. ${ }^{3}$

The infusions were carried out using a spray catheter probe (Endoflex, Germany), which was introduced into the infusion canal of the endoscope. The infusions were directed to an area located $15 \mathrm{~cm}$ above the Z-line and were performed at a low rate (a total volume of $20 \mathrm{ml}$ over 10 $\min )$.

Two esophageal samples were collected before the infusion and another two samples were collected afterwards. The biopsies were performed using 6-mm traditional biopsy forceps (Wilson-Cook, Winston-Salem, NC, USA).

The biopsies obtained from patients presenting with normal esophageal mucosa were taken at $10 \mathrm{~cm}$ above the Z-line. In patients with erosive esophagitis, the biopsies were taken from the most adjacent area of the erosion. Erosive esophagitis was diagnosed based on the Los Angeles classification. ${ }^{1,17}$

Following the biopsies taken after infusion of $\mathrm{HCl}$, patients received an infusion of an alkaline (aluminum 
hydroxide) solution $(61.5 \mathrm{mg} / \mathrm{ml})$ in order to neutralize the acid. Antacids were prescribed for patients who received $\mathrm{HCl}(15 \mathrm{ml}$ orally, four times in the first $24 \mathrm{~h}$ after the procedure).

In each situation, one tissue sample was used for histopathological analysis using light microscopy and the other for electron microscopy studies.

\section{Microscopy}

For light microscopy, the specimens were fixed in formalin and stained with hematoxylin and eosin. All histopathological analyses were performed by a single pathologist who was blinded to the clinical details and exposure protocol. The histological findings were classified and graded according to the Ismail-Beigi criteria. ${ }^{4}$

For electron microscopy, small tissue samples were fixed with $2 \%$ glutaraldehyde in $0.15 \mathrm{M}$ phosphate buffer at $\mathrm{pH} 7.2$, followed by post-fixation in $1 \%$ osmium tetroxide dissolved in saline and impregnation overnight in an aqueous solution of $1 \%$ uranyl acetate.

Samples were embedded in polyester resin, and ultrathin sections were cut on an ultramicrotome (LKB Instruments, Rockville, MD, USA). The sections were then double stained with lead citrate and uranyl acetate and examined under an electron microscope using a model JEM 1010 microscope (JEOL, Tokyo, Japan).

\section{Morphometric analysis}

For each sample, three electron micrographs were taken ( $\times 8400$ magnification) from an area of the suprabasal layer of the esophageal epithelium. Morphometric analysis of intercellular space was performed using the computer software Image J (National Institute of Health, USA). For each sample, 30 measurements (10 per electron micrograph) were made, and the intercellular space width (ISW) was quantified in nanometers. The ISW was considered dilated for measurements greater than 1.80 nanometers. ${ }^{8,11}$

The percentage of differences between pre-infusion and post-infusion and the mean value of ISW for each patient were calculated using the formula:

$\Delta \%=\frac{\overline{\mathrm{ISW}}_{\text {pre-infusion }}-\overline{\mathrm{ISW}}_{\text {post-infusion }}}{\overline{\mathrm{ISW}}_{\text {pre-infusion }}} \times 100$

\section{Statistics}

Quantitative variables are expressed as absolute (n) and relative (\%) frequencies, whereas quantitative variables are expressed as means, standard deviations and ranges (minimum and maximum values). Due to the small sample size and significant internal variation, nonparametric tests were applied. The nonparametric Mann-Whitney test was used to compare the two types of infusion and to compare the two groups in terms of the values from the electron microscope. It was also used to test the percentage variation before and after infusion. P-values $<0.05$ were considered significant $(\alpha=5 \%)$.

\section{RESULTS}

Of the 44 patients evaluated, 15 were excluded because they presented with clinical profiles consistent with GERD without erosive lesions. The mean age of the study sample was 44.2 years.

The final cohort consisted of 29 patients: 11 with erosive esophagitis (Lesion group, L) and 18 with no damage to the esophageal mucosa (Control group, C). The L group was composed of five females and six males, whereas the $\mathrm{C}$ group consisted of 11 females and seven males.

In the histological evaluations performed prior to and after the $\mathrm{NaCl}$ or $\mathrm{HCl}$ infusions, all 11 patients in the $\mathrm{L}$ group had chronic esophagitis. Of the 18 patients in the C group, 11 were diagnosed histologically with chronic esophagitis. The histological diagnosis, however, was normal for three of the patients in the group receiving an $\mathrm{NaCl}$ infusion (only prior to infusion) and four of the patients in the group receiving an $\mathrm{HCl}$ infusion (prior to and after infusion).

After the infusion of $\mathrm{NaCl}$, the histological diagnosis of one patient (11.1\%) changed from mild chronic esophagitis to normal. The infusion of $\mathrm{HCl}$, however, did not alter the histological profile of any patient.

The DIS values prior to and after $\mathrm{NaCl}$ or $\mathrm{HCl}$ infusions are shown in Table 1.

No significant differences were found at the electron microscope level or in the morphometric analysis among the various combinations of symptom groups (i.e., with and without UGIE evidence of erosive esophagitis) or infusion groups (i.e., $\mathrm{C}$ and $\mathrm{L}$ ) ( $\mathrm{p}>0.05$ for all comparisons) (Tables 2 and 3; Figures 1 and 2).

\section{DISCUSSION}

The present study aimed to compare the ultrastructural alterations (dilated intercellular space) of the esophageal mucosa in patients with UGIE-proven typical GERD and erosive esophagitis (L Group) to patients without GERD symptoms and presenting with normal UGIE results (C Group).

Since DIS was reported to be a potential precursor of GERD, it has taken center stage in the global scientific literature. With the objective of evaluating this affirmation, we therefore infused $\mathrm{HCl}$ or $\mathrm{NaCl}$ into the esophageal 
Table 1 - Electron microscopy results showing pre-infusion values, post-infusion values and variations between the two

\begin{tabular}{lccc}
\hline \multirow{2}{*}{ Group } & \multicolumn{3}{c}{ Width of the intercellular space } \\
\cline { 2 - 4 } & Before $(\mathrm{nm})$ & After $(\mathrm{nm})$ & Variation $(\%)$ \\
\hline Control Group -C/ & $7.158(3.643)$ & $7.210(3.379)$ & $14.44(57.54)$ \\
With NaCl infusion $(\mathrm{n}=9)$ & 5.725 & 6.864 & 8.62 \\
\hline Control Group -C / & $10.062(5.672)$ & $8.965(5.379)$ & $-7.96(28.43)$ \\
With HCl infusion $(\mathrm{n}=9)$ & 10.219 & 7.346 & -2.81 \\
\hline Lesion Group- $\mathrm{L} /$ & $8.397(3.820)$ & $5.506(2.728)$ & $-26.66(33.10)$ \\
With NaCl infusion $(\mathrm{n}=6)$ & 8.580 & 4.342 & -27.07 \\
\hline Lesion Group- $\mathrm{L} /$ & $10.203(4.565)$ & $8.404(2.370)$ & $-7.62(34.89)$ \\
With HCl infusion $(\mathrm{n}=5)$ & 8.572 & 8.466 & 0.79 \\
\hline
\end{tabular}

Table 2 - Comparison among the various combinations of groups (patient groups $\mathrm{C}$ and $\mathrm{L}$ observed via an upper gastrointestinal endoscopy and receiving infusion of either $\mathrm{HCl}$ or $\mathrm{NaCl}$ ) in terms of electron microscopy results (i.e., the morphometric analysis)

\begin{tabular}{lc}
\hline Group & $\mathrm{p}_{1}$ \\
\hline Group C: $\mathrm{NaCl}$ vs. $\mathrm{HCl}$ - Pre-infusion & 0.233 \\
Group C: $\mathrm{NaCl}$ vs. $\mathrm{HCl}$ - Post-infusion & 0.627 \\
Group C: $\mathrm{NaCl}$ vs. $\mathrm{HCl}$ - Variation (\%) & 0.310 \\
Group L: $\mathrm{NaCl}$ vs. $\mathrm{HCl}$ - Pre-infusion & 0.715 \\
Group L: $\mathrm{NaCl}$ vs. $\mathrm{HCl}$ - Post-infusion & 0.068 \\
Group L: $\mathrm{NaCl}$ vs. $\mathrm{HCl}$ - Variation (\%) & 0.584 \\
\hline
\end{tabular}

$\mathrm{p}_{1}$ : Mann-Whitney test

Table 3 - Comparison between the electron microscopy (morphometric analysis) results for patients group "L" and "C" by infusion type

\begin{tabular}{lc}
\hline Compares groups & $\mathrm{p}_{1}$ \\
\hline $\mathrm{NaCl}$ : Group C vs. Group L - Pre-infusion & 0.480 \\
$\mathrm{NaCl}$ : Group C vs. Group L - Post-infusion & 0.346 \\
$\mathrm{NaCl}$ : Group C vs. Group L - Variation (\%) & 0.077 \\
$\mathrm{HCl}$ : Group C vs. Group L - Pre-infusion & 0.841 \\
$\mathrm{HCl}$ : Group C vs. Group L - Post-infusion & 0.641 \\
$\mathrm{HCl}$ : Group C vs. Group L - Variation (\%) & 0.947 \\
\hline
\end{tabular}

$\mathrm{p}_{1}$ : Mann-Whitney test

mucosa during the final phase of the endoscopic examinations. This was done in order to detect the occurrence of DIS in patients with normal esophageal mucosa or with erosive esophagitis.

It has been proposed that the increased paracellular permeability caused by DIS is responsible for the development of pyrosis in the absence of esophageal lesions. This hypothesis is plausible, as there are sensory neurons

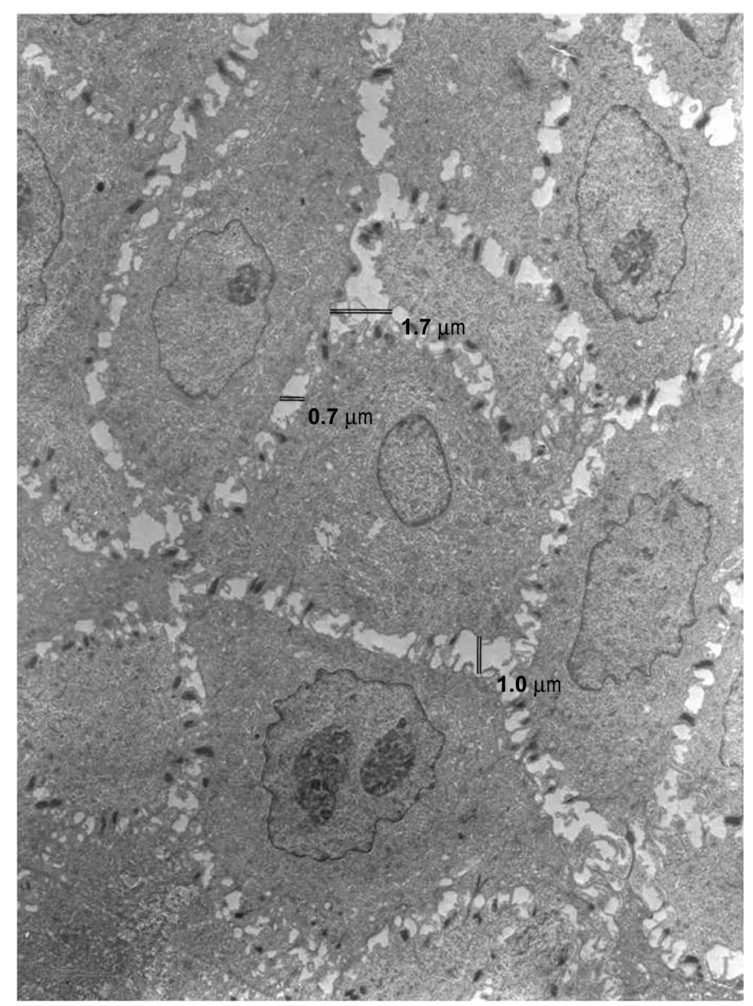

Figure 1 - Electron micrograph of the prickle cell layer of the esophageal epithelium from a patient with a normal esophagus prior to $\mathrm{HCl}$ infusion (magnification, $\times 8400$ )

and receptors in the intercellular region. ${ }^{18}$ The increased permeability is due to the presence of acid-sensitive nocireceptor models that maintain pyrosis through the chemical stimulation of intra-epithelial nerve terminals, which are located within or just below the squamous epithelium of the esophageal mucosa. The stimulation occurs because of the increased permeability of the esophageal epithelium and the consequent acid-related damage to the epithelium..$^{13,19}$

When evaluating the histological characteristics of the esophageal mucosa, we observed that $\mathrm{HCl}$ infusions did not alter the histological pattern. In patients of the $\mathrm{C}$ Group and in those with normal mucosa (as determined through light 


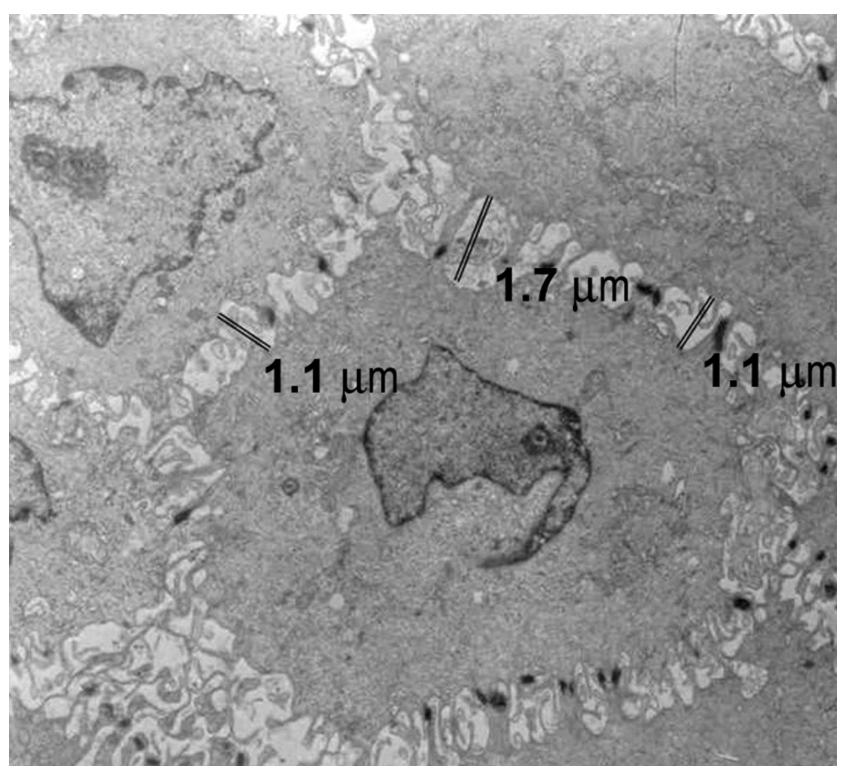

Figure 2 - Electron micrograph of the prickle cell layer of the esophageal epithelium from a patient with a normal esophagus following $\mathrm{HCl}$ infusion (magnification, $\times 8400$ )

microscopy), no post-infusion ultrastructural alterations were observed. The diagnosis changed in only one patient in the $\mathrm{C}$ Group after infusion of $\mathrm{NaCl}$. In this patient, the light microscopy finding was adjusted from mild esophagitis to normal. Alterations in the esophageal mucosa, however, are non-specific, leading to different diagnoses when multiple pathologists analyze the same biopsy samples. ${ }^{6}$

After infusion of $\mathrm{HCl}$, patients in the $\mathrm{C}$ Group presented with greater reductions in DIS than patients of the L Group $(p=0.641)$. From these results, it can be inferred that cellular edema and, consequently, a reduction in the size of the intercellular space occurred after the acid infusion. Nevertheless, the erosive esophageal epithelium also had cellular edema, albeit to a lesser intensity. This allowed us to generate the hypothesis that there is a lower response of cellular ion transport mechanisms (i.e., active absorption of sodium and diffusion of hydrogen ions) and that paracellular permeability induces the movement of water through tissues. The infusion of $\mathrm{HCl}$ has been shown to induce cellular edema in the esophageal epithelia of rabbits, demonstrating that this alteration was time- and $\mathrm{pH}$-dependent. In that study, the authors took into account that such an alteration could lead to cell volume regulation. ${ }^{20}$

After the infusion of $\mathrm{NaCl}$, esophageal epithelium in the L Group presented with more marked reductions in the size of the intercellular space. We hypothesize that this effect is different from that observed in normal epithelia, in which the cell volume reduction, together with the consequent increase in the intercellular space, likely occurred after infusion of $\mathrm{NaCl}$. The marked edema observed in the erosive epithelia could have resulted from the osmolarity gradient and from alteration of the epithelial cellular ion transport mechanisms, which are regulated by the $\mathrm{NaK}_{2} \mathrm{Cl}$ cotransporter. ${ }^{20}$

The values found for DIS width were higher than those described previously. ${ }^{8,11}$ This includes the values observed in the C Group, in whom the mean of the DIS width were lower than those of the L Group. This discrepancy can be explained by the different methodologies employed. The sections were cut to a fixed thickness of 3 to 5 cells above the blade, a technique not employed in other studies. ${ }^{14}$ It is also of note that the electron micrographs used were enlarged to a magnification of $\times 8400$, unlike the $\times 2500$ and $\times 5400$ magnifications used by other authors. ${ }^{12,14,20}$ These differences in magnification could be responsible for the inconsistent results.

In addition, histological and electron microscopy alterations occurred after the infusion of $\mathrm{HCl}$. Nevertheless, it is questionable whether infusion volume and duration were sufficient to induce DIS and whether a histological alteration indeed occurred. This question arises due to the fact that the infusion time used $(10 \mathrm{~min})$ corresponds to only $0.03 \%$ of the total time between evaluations $(24 \mathrm{~h})$. In the first esophageal pH-metry, when the catheter was positioned within $5 \mathrm{~cm}$ of the lower esophageal sphincter, normal results are obtained in up to $4 \%$ of all examinations. To avoid prolonging the duration of the examination and the intravenous sedation, longer infusion times were not used in the present study.

In a previous study, acid and saline perfusion of the esophageal epithelium was performed and induced a slight increase in the height of the basal cell layer in the control group. Moreover, the perfusion induced increases in DIS in healthy patients; however, no histological changes regarding DIS in GERD patients occurred. There was a difference of a 10 or $30 \mathrm{~min}$ infusion period between healthy and GERD patients, respectively. Furthermore, the infusion was performed by a double lumen nasogastric catheter instead of a gastroscopy, and both analyses had a limited number of individuals. $^{2}$

To obtain more valid conclusions as to the usefulness of $\mathrm{HCl}$ infusion, it would be necessary to analyze a greater number of patients. In addition, we believe that there is a need for more in-depth studies on ion transport mechanisms occurring in the mucosa of erosive lesions. Our findings suggest that the osmolarity difference of the esophageal lumen in tissues exposed to $\mathrm{HCl}$ and $\mathrm{NaCl}$ occurs in both damaged and healthy mucosa. Furthermore, the results of this study suggest that alterations in cell volume after infusion of such substances need to be investigated.

The greatest contribution resulting from the study of the esophageal epithelium intercellular space would likely be the discovery of a histochemical marker for cellular junctions, 
which would allow the creation of a GERD marker for effective and routine use in clinical practice. Some authors are studying desmosomal proteins and attempting to express them in GERD and NERD patients. ${ }^{22}$

\section{CONCLUSIONS}

In patients with typical GERD symptoms and erosive esophagitis, there was no significant difference in the effect on the intercellular space after a 10-min infusion of $0.1 \mathrm{~N}$ $\mathrm{HCI}$ or $0.9 \% \mathrm{NaCl}$. The same was true in patients without typical GERD symptoms.

\section{ACKNOWLEDGEMENT}

The authors are grateful to Mrs. Roberta Blanco for her help with the preparation of the manuscript.

\section{REFERENCES}

1. Moraes-Filho J, Cecconello I, Gama-Rodrigues J, Castro L, Henry MA, Meneghelli UG, et al. Brazilian consensus on gastroesophageal reflux disease: proposals for assessment, classification, and management. Am J Gastroenterol. 2002;97:241-8.

2. Moraes-Filho J, Chinzon D, Eisig J, Quilici F, Zaterka S. Brazilian National Surveillance on Heartburn. In: Gastroenterology. 2003;2003:A166

3. Navarro-Rodriguez T, de Moraes-Filho JP, Arakaki E, Chinzon D, Zaterka S, Iriya K, et al. The screening sensitivity of endoscopy, acid perfusion test and 24-hour $\mathrm{pH}$-monitoring to evaluate esophagitis in patients with heartburn and histological esophagitis. Arq Gastroenterol. 1997:34:148-56.

4. Ismail-Beigi F, Horton PF, Pope CE. 2nd: Histological consequences of gastroesophageal reflux in man. Gastroenterology. 1970;58:163-74.

5. Vieth M, Peitz U, Labenz J, Kulig M, Nauclér E, Jaspersen D, et al. What Parameters are relevant for the Histological Diagnosis of Gastroesophageal Reflux Disease without Barrett`s Mucosa? Dis Dis. 2004;196-201.

6. Takubo K, Honma N, Aryal G, Sawabe M, Arai T, Tanaka Y, et al. Is there a set of histologic changes that are invariably reflux associated? Arch Pathol Lab Med. 2005;129:159-63.

7. Riddell RH. The biopsy diagnosis of gastroesophageal reflux disease, "carditis," and Barrett's esophagus, and sequelae of therapy. Am J Surg Pathol. 1996;20 Suppl 1:S31-50.

8. Calabrese C, Fabbri A, Bortolotti M, Cenacchi G, Areni A, Scialpi C, et al. Dilated intercellular spaces as a marker of oesophageal damage: comparative results in gastro-oesophageal reflux disease with or without bile reflux. Aliment Pharmacol Ther. 2003;18:525-32.

9. Tobey NA, Carson JL, Alkiek RA, Orlando RC. Dilated intercellular spaces: a morphological feature of acid reflux--damaged human esophageal epithelium. Gastroenterology. 1996;111:1200-5.

10. Cicala M, Emerenziani S, Caviglia R, Guarino MP, Vavassori P, Ribolsi $\mathrm{M}$, et al. Intra-oesophageal distribution and perception of acid reflux in patients with non-erosive gastro-oesophageal reflux disease. Aliment Pharmacol Ther. 2003; 18:605-13.

11. Caviglia R, Ribolsi M, Gentile M, Rabitti C, Emerenziani S, Guarino MPL, et al. Dilated intercellular spaces and acid reflux at the distal and proximal oesophagus in patients with non- erosive gastro oesophageal reflux disease. Aliment. Pharmacol Ther. 2007;25:629-36.
12. Tobey NA, Hosseini SS, Argote CM, Dobrucali AM, Awayda MS, Orlando RC. Dilated intercellular spaces and shunt permeability in nonerosive acid-damaged esophageal epithelium. Am J Gastroenterol. 2004;99:13-22.

13. Vieth M, Fiocca R, Haringsma J, Delarive J, Wiesel PH, Tam W, et al. Radial distribution of dilated intercellular spaces of the esophageal squamous epithelium in patients with reflux disease exhibiting discrete endoscopic lesions. Dig Dis Sci. 2004;22:208-12.

14. Solcia E, Villani L, Luinetti O, Trespi E, Strada E, Tinelli C, et al. Altered intercellular glycoconjugates and dilated intercellular spaces of esophageal epithelium in reflux disease. Virchows Arch. 2000;436:20716

15. Calabrese C, Bortolotti M, Fabbri A, Areni A, Cenacchi G, Scialpi $\mathrm{C}$, et al. Reversibility of GERD ultrastructural alterations and relief of symptoms after omeprazole treatment. Am J Gastroenterol. 2005; 100:537-42.

16. Calabrese C, Fabbri A, Bortolotti M, Cenacchi G, Carlo S, Zahlane D, et al. Effect of omeprazole on symptoms and ultrastructural esophageal damage in acid bile reflux. World J Gastroenterol. 2005;11:1876-80.

17. Armstrong D, Bennett JR, Blum AL, Dent J, De Dombal FT, Galmiche JP, et al. The endoscopic assessment of esophagitis: a progress report on observer agreement. Gastroenterology. 1996;111:85-92.

18. Rodrigo J, Hernandez CJ, Vidal MA, Pedrosa JA. Vegetative innervation of the esophagus. III. Intraepithelial endings. Acta Anat (Basel). $1975 ; 92: 242-58$.

19. Kahrilas PJ. Dilated intercellular spaces: extending the reach of the endoscope. Am J Gastroenterol. 2005;100:549-50.

20. Tobey NA, Jr. Cragoe EJ, Orlando RC. HCl-induced cell edema in rabbit esophageal epithelium: a bumetanide-sensitive process. Gastroenterology. 1995; 109:414-21.

21. Bove M, Vieth M, Drombrowski F, Ny L, Ruth M, Lundell L. Acid challenge to the human esophageal mucosa: effects on epithelial architecturein health and disease. Dig. Dis. Sci. 2005;50:1488-96.

22. Monkemuller K, Stahs A, Fry LC, Wex T, Volkel S, Malfertheiner P. The desmosomal proteins desmoglein and plakoglobin are up regulated in patients with both non erosive and erosive gastroeosphageal reflux as compared to asymptomatic controls. Gut. 2007;56(Suppl III) A14. 